\title{
Events and Announcements
}

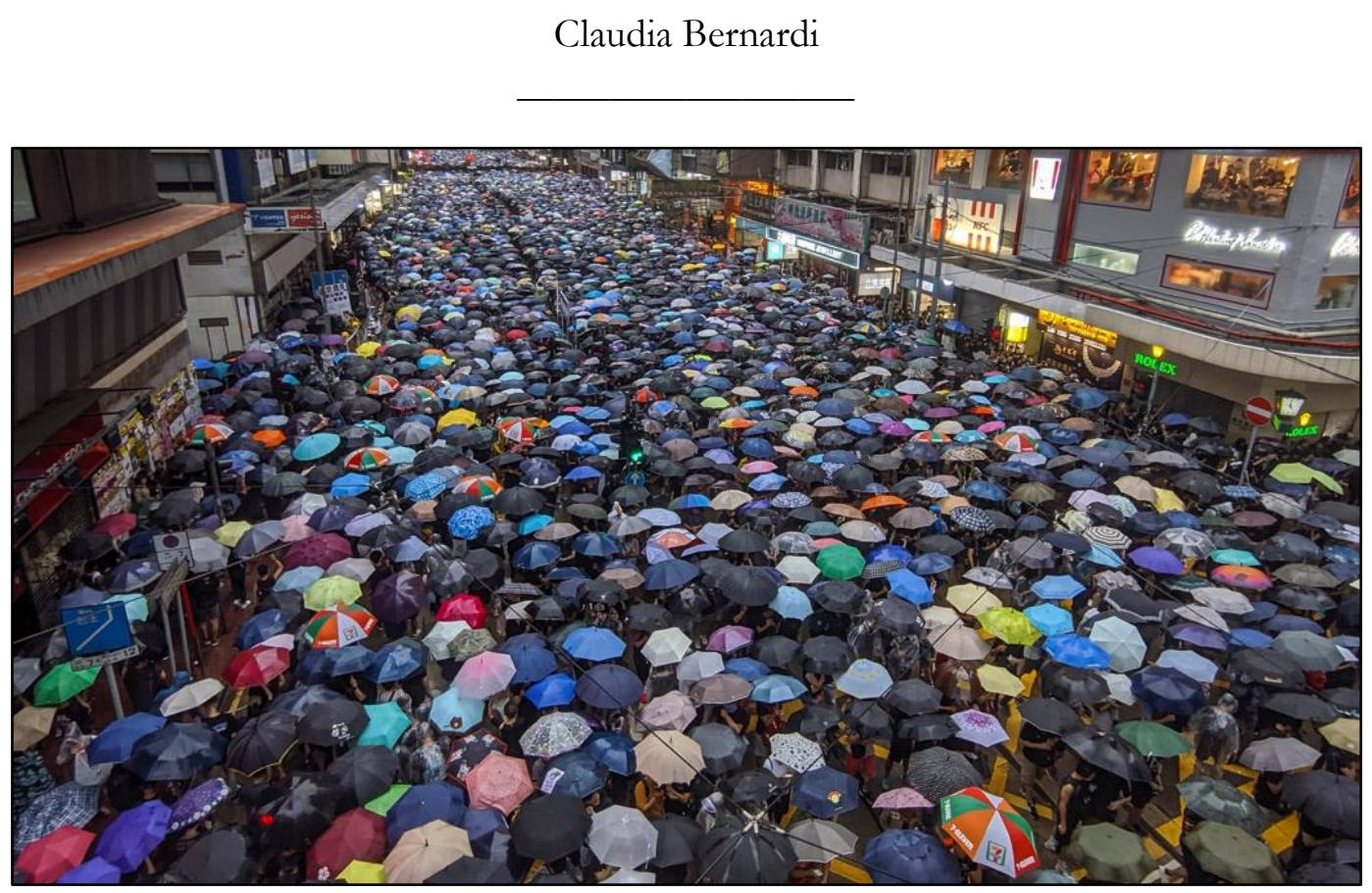

Photo source: Wikipedia Commons

This section aims to improve communications between initiatives, artists, activists, scholars, and research groups engaged in the study and politics of commodity frontiers. Here you will find the latest news recommended by people participating in the Commodity

Frontiers Initiative.

The focus of this issue is mineral frontiers. Announcements below are for research schools, workshops, social movement calls for action, conferences, exhibitions, and calls for papers from various regions of our planet for fostering debate about mineral frontiers, extractivism, environmental humanities, ecologies, and other issues.

This is a first selection, and we would be happy to add further events on our website and in future volumes of Commodity Frontiers. Please send your announcements to Claudia Bernardi (clod.zeta@gmail.com) and Mindi Schneider (mindi.schneider@wur.nl), or contact us through the website, Twitter, or Facebook.

\section{Correspondence:}

Claudia Bernardi, clod.zeta@gmail.com

Cite this article:

Bernardi, C. 2020. "Events and Announcements." Commodity Frontiers 1: 54-58. doi: 10.18174/CF.2020a17972.

Commodity Frontiers is an open-access journal edited by the CFI Editorial Board, Mindi Schneider, senior editor. Read it online at Commodity Frontiers, or our website, commodityfrontiers.com.

This work is licensed under a Creative Commons Attribution-NonCommercial 4.0 International License.

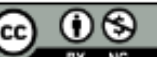




\section{Upcoming Workshops, Webinars, and Conferences}

\section{ETROD- Extractivism and Transition Research Online Dialogues}

14/09/2020- 08/02/2020

CityIndustries. International Research Network

Several workshops and conferences bring together social science scholars to discuss, exchange and further develop research particularly on transition to post-carbon futures, resources, energy, infrastructures and extractivism.

https://cityindustries.org/activities/extractivism-and-transition-research-online-dialogues-sep-

2020-feb-2021

Webinar Series "Towards a Responsible Supply Chain for Electronics. From Mining to Manufactory"

28/09/2020-02/10/2020

Make ICT Fair project

In three webinars, the different links of the ICT supply chain, from mineral extraction to manufacturing and assembly are analysed to stimulate an open discussion with the sector to achieve a fairer supply chain for electronic devices.

https://catapa.be/en/webinar-series-towards-a-responsible-supply-chain-forelectronics $/$ ?utm source $=$ rss\&utm medium $=$ rss\&utm campaign $=$ webinar-series-towards-aresponsible-supply-chain-for-electronics

\section{European Webinar on the Right to Say No! European Struggles and Successes}

29/09/2020

CIDSE- Together for Global Justice

The Webinar series is a continuation of the work of the TSF in terms of consolidating a broad movement of resistance in order to build common struggles for solidarity.

https://www.cidse.org/? event=the-right-to-say-no-european-struggles-and-successes

\section{Interdisciplinary Autumn Research School: Rethinking Extractivist Capitalism}

$10-18 / 10 / 2021$

University of Bremen

The Autumn School will address the political economy of extractivist accumulation, its ecological and social implications, and questions of dissent, protest and resistance.

https://yisares.uni-bremen.de/

EXALT Symposium 2020. Extractivisms and Alternatives

$21-23 / 10 / 2020$

EXALT- Initiative 
The event draws together diverse critical analyses of the phenomena of global extractivisms and the myriad alternatives pursued both in theory and practice.

https://www.helsinki.fi/en/conferences/exalt-2020/exalt-symposium-2020

\section{Conference "Challenging Crops and Climates" - AHS conference 2021}

$2-5 / 06 / 2021$

People have transformed environments to meet the demands of agricultural production through both private and state-sponsored actions. The Agricultural History Society encourages submissions that explore how farmers and other rural people wrestle with challenging and changing environments.

https://www.aghistorysociety.org/2021-meeting

\section{Calls for Papers}

CFP: Extractivism in the Americas working group: call for participants and paper proposals

Deadline: $15 / 10 / 2020$

This working group provides a network to appraise the histories and legacies of neoextractivism in Latin America and the Caribbean. Our immediate aims are to organize panels for the 2021 Congress of the Canadian Association of Latin American and Caribbean Studies, and to produce a special edition of the Canadian Journal of Latin American and Caribbean Studies.

https://networks.h-net.org/node/23910/discussions/6447896/postextractivism-americasworking-group

\section{CFP: Comparing the Copperbelt: Social History and Knowledge Production in Central} Africa

Deadline: $15 / 10 / 2020$

University of Oxford

The project aims to examine the Copperbelt (in both Zambia and the DR Congo) as a single region divided by a (post-)colonial border, across which flowed minerals, people and ideas. http://copperbelt.history.ox.ac.uk/

\section{CFP: Rethinking Tobacco History: Commodities, Empire and Agency in Global Perspective, 1780-1960}

Deadline: 15/11/2020

University of Cologne

The conference will be held at the University of Cologne, December 1-4, 2021. We seek to have a good representation of women, scholars based in the Global South, postdocs, and doctoral candidates. 
https://networks.h-net.org/node/23910/discussions/6396192/cfp-rethinking-tobacco-historycommodities-empire-and-agency

\section{CFP: Routledge Handbook of the Digital Environmental Humanities}

Deadline: 01/01/2021

DEH is empirically, critically and ethically engaged in exploring digitally mediated, visualized, and parsed framings of past, present and future environments, landscapes and cultures, as well as the ways in which these operate to produce scale, from the intimate and personal to the global and planetary. https://networks.h-net.org/node/73374/announcements/6460492/call-chapter-contributionsroutledge-handbook-digital

\section{Calls for Proposals}

CfP: Unskewing the Data Value Chain - A Policy Research Project for Equitable Platform Economies

Deadline 20/10/2020

IT for Change seeks to collaborate with researchers and scholars working on issues of the digital economy and data governance in the Global South for our exciting new research project, 'Unskewing the Data Value Chain - A Policy Research Project for Equitable Platform Economies'. Supported by the Omidyar Network, this project aims to generate high-quality, original, evidence-based research, and build a robust body of work to inform policymakers and practitioners and recommend policy directions for inclusive and equitable data value chains in the platform economy. Towards this, we seek to forge collaborations for research studies outside India* and build an interdisciplinary network of scholars and researchers in a cutting-edge policy domain. We will award up to seven grants of USD 13,500 each for a period of 12 months. https://itforchange.net/call-for-proposals-unskewing-data-value-chain-policy-research-projectfor-equitable-platform

\section{Vacancies and Residencies}

\section{Assistant/Associate Professor in Environmental Humanities}

Deadline: $16 / 10 / 2020$

Swarthmore College

We seek applications from scholars who foreground Indigeneity in their environmental research and whose work seeks to advance humanistic understandings of environmental challenges such as climate change, water and land access and governance, food sovereignty, and public health. https://www.h-net.org/jobs/job display.php?id=60277 


\section{Assistant Professor}

Deadline: $17 / 10 / 2020$

Ashoka University

The Department of History at Ashoka University invites applications for full-time faculty positions. The positions are in Ancient History/Archaeology, Modern Indian History and Global History.

https://facultypositions.ashoka.edu.in/JD/History JD 1st September 2020.pdf

\section{Residency Program}

Art Explora - Cité Internationale des arts

The Art Explora Foundation together with Cité internationale des arts collaborate to coconstruct a unique program for French and international artists and researchers. The first residency session will begin in March 2021.

https://artexplora.org/en/residency-program-art-explora-cite-internationale-desarts/?fbclid=IwAR2haqNExA6NsBiGwjcd6duxZ4axldhy260IIybobVqXLpMHRN8gPge5eN8

\section{Exhibitions}

Raw Materials

Johann Jacobs Museum

Zurich, Switzerland

What is human history about if not the distribution of scarce resources? Entire epochs (think the Iron Age) are named after raw materials. And people are prepared to kill to secure sources of raw materials, we know that. Cocoa and the coffee are rife with nice and terrible stories. The same can be said of gold, crude oil, rubber and rare earths. Telling these stories is one thing. Being able to interpret them is another matter entirely. And yet that is exactly what our exhibitions aim to do: use raw materials as a guide for deciphering how our modern world works.

http://johannjacobs.com/en/arbeitsfelder/raw-materials/

\section{Other Announcements}

\section{Open Letter to European Commission from CSOs on Critical Raw Materials Plans} $10 / 04 / 2020$

Civil Society Organizations

A group of civil society organizations are coordinating a sign-on letter calling on the European Commission to change course on its proposed policies on mining raw materials critical for renewable energy. You can view the letter in the link below, and find information on the Yes to Life No to Mining global and EU groups. https://www.gaiafoundation.org/ec-we-cant-mine-our-way-out-of-the-climate-crisis/ 